\title{
EDITORIAL
}

\section{Medicina do trabalho em tempos de COVID-19: a importância do cuidado integral à saúde do trabalhador}

\author{
Occupational medicine in times of COVID-19: the importance of \\ comprehensive health care for workers
}

\section{Marcelo Pustiglione}

Em 11 de março de 2020, a Organização Mundial da Saúde (OMS) declarou como pandemia uma doença infectocontagiosa caracterizada por síndrome respiratória aguda severa (severe acute respiratory syndrome - SARS) causada por um tipo novo de coronavírus, denominado SARS-CoV-2. Próximo a esta data, o Ministério da Saúde do Brasil informou a ocorrência de casos autóctones desta virose alertando para o início da transmissão comunitária ou sustentada da doença.

Mas, a história clínica e epidemiológica da COVID-19 tem seu "início oficial" em 31 de dezembro de 2019, quando o Escritório da OMS na China foi informado sobre casos de pneumonia de etiologia desconhecida ocorridos na cidade de Wuhan, província chinesa de Hubei. Desde aquela data até 3 de janeiro de 2020, um total de 44 pacientes com pneumonia de etiologia desconhecida foi notificado à OMS pelas autoridades nacionais da China. Em 7 de janeiro de 2020, as autoridades chinesas revelaram ter identificado e isolado em pessoas com a doença um "novo tipo de coronavírus". Em 12 de janeiro a China compartilhou para os países usarem no desenvolvimento de kits de diagnóstico específicos a sequência genética do agente confirmado em laboratório de Wuhan, denominado "2019-nCoV". Deste fato histórico advém as denominações do vírus (SARS-CoV-2) e da pandemia coronavirus disease - 2019, que acabou gerando a sigla "COVID-19".

No Brasil, em 16 de janeiro, em reunião da Coordenação-Geral de Emergência em Saúde Pública (CGEMSP/DSASTE) foi elaborado um Protocolo de Vigilância; no dia seguinte (17 de janeiro) foi publicado Boletim Epidemiológico da Secretaria de Vigilância Sanitária (SVS) do Ministério da Saúde (MS) tratando do assunto ${ }^{1}$.Em 26 de fevereiro de 2020, foi confirmado pelo MS, o primeiro caso de COVID-19 no Brasil, não autóctone. De lá para cá o número de casos aumentou exponencialmente no país com epicentro na região

Professor Convidado da Disciplina de Medicina do Trabalho nos cursos de Graduação e Pós-Graduação e Preceptor do Programa de Residência Médica em Medicina do Trabalho do Departamento de Medicina Legal, Ética Médica, Medicina Social e do Trabalho do Instituto Oscar Freire da Faculdade de Medicina da Universidade de São Paulo. https://orcid.org/0000-0003-2195-915X. E-mail: cepah. marcelo@gmail.com 
sudeste, especialmente na cidade de São Paulo. Em 12 de janeiro, quando escrevíamos este texto, próximo de cumprir um ano do primeiro caso no país, tínhamos contabilizado no Brasil 8.256.536 casos confirmados, 205.964 mortes, 7.316 .944 casos recuperados e 733.628 casos em acompanhamento 2 .

Neste um ano de COVID-19 todos nós estamos tendo a oportunidade de experimentar a sensação de enfrentar "algo" desconhecido. Motivador para alguns. Assustador para muitos. Útil para os oportunistas. Por um lado, esta experiência mostrou quão solidárias, altruístas e comprometidas as pessoas podem ser. Por outro lado pôs à mostra a situação crítica de nosso sistema de saúde vítima da má gestão, desmonte, abandono e sucateamento ao longo das últimas décadas.

Planos de contingência apoiados pelo Decreto Legislativo $\mathrm{N}^{\circ} 6$ de 18 de março de 2020 que reconheceu a ocorrência de estado de calamidade pública no país, dispensavam licitação na compra dos insumos necessários para o enfrentamento da doença. Porém, ao mesmo tempo que dava agilidade à gestão, escancarava atos criminosos desde desvios de verba até compra de insumos sem a mínima qualidade necessária, incluindo equipamentos de proteção para trabalhadores. Estes desmandos e a impunidade abalaram mais ainda o ânimo das pessoas em geral.

Agregue-se a isso notícias falsas, interpretações falaciosas, comentários tendenciosos, politização da ciência, etc. e temos um cenário completo determinante de estresse, instabilidade emocional do povo, baixa autoestima e comportamentos violentos.

No bojo da "angústia coletiva relacionada ao COVID-19" certamente está seu elevado poder de infectar pessoas e a necessidade de isolamento e distanciamento social.

Em 12/01/2021, 3,9\% da população brasileira testou positivo para COVID. Este fato, porém, deve estar relacionado à falta de testagem e subnotificação dos casos. Além disso, a COVID-19 tem se mostrado capaz de causar quadros inflamatórios severos e graves que necessitam de internação, isolamento hospitalar e assistência intensiva trazendo grande sofrimento para a pessoa afetada e para seus parentes e levando à morte 2,49\% dos casos confirmados. Deve-se considerar que este índice de mortalidade está baseado nos números de casos confirmados em 12/01/2021, podendo mudar conforme mais testes sejam realizados em casos suspeitos ${ }^{2}$.

Na realidade, ainda hoje, a única certeza que temos é que o cenário epidemiológico da COVID-19 ainda está em fase de construção. Os números serão diferentes quando for testado percentual significativo da população e quando todos os casos forem corretamente diagnosticados e adequadamente notificados.

Porém, considerando o princípio da prevenção para doença infectocontagiosa, e sem entrarmos no mérito das decisões tomadas, foram adotadas rígidas medidas de controle com ênfase no isolamento social amplo com o objetivo de "achatar a curva" buscando evitar o colapso do sistema de saúde. Em decorrência a economia do país foi profundamente afetada, milhões de pessoas perderam seus empregos, milhares de empresas fecharam definitivamente suas portas e a esmagadora maioria delas tentam buscar recursos e meios para começar a retomar suas atividades, mesmo aquelas consideradas essenciais. Em decorrência, hoje em dia, grande parte dos trabalhadores ou está desempregada, ou está subempregada ou está empregada com receio de perder o emprego.

Desta forma, os trabalhadores, qualquer que seja a condição que estejam dentre as acima citadas, vivem, nos dias de hoje, situação de apreensão que oscila, continua e permanentemente, entre o medo de adoecer, o de perder seu emprego e o de deixar de ter uma fonte de rendimento. É inegável e evidente o impacto destes determinantes sociais na saúde física e mental das pessoas de uma forma em geral e nos trabalhadores em especial. Particularmente algumas categorias de trabalhadores tem este cenário potencializado pela possibilidade de exposição ocupacional ao vírus e risco de adoecer, e, como no caso dos trabalhadores de serviços de saúde, pelo contato próximo com o sofrimento das pessoas, doentes e familiares. Foram relatados 
inclusive alguns atos de violência e preconceito contra "trabalhadores da saúde" nas ruas, coletivos e no próprio ambiente de trabalho por associar-se estes profissionais ao risco de aquisição da doença. Diante deste cenário, nos primeiros meses de pandemia, quantidade considerável destes profissionais abandonaram seus empregos e vagas não foram preenchidas por "medo de levar a doença para casa" ou por pressão familiar e social. Consequência: sobrecarga de trabalho, turnos dobrados, aumento do estresse relacionado ao cumprimento de metas e frustração pelas perdas inevitáveis ... e, o pior, algumas evitáveis caso os recursos necessários estivessem disponíveis em quantidade suficiente.

Muito justamente, desde o início de 2020, a maioria dos holofotes estão focados nos infectologistas e microbiologistas que buscam sem descanso tratamento e vacina e nos profissionais da saúde que estão na linha de frente da assistência dos doentes correndo risco pessoal de adoecimento e morte. Neste texto, e considerando o grande impacto da COVID-19 na saúde dos trabalhadores anteriormente apontado pedimos permissão para direcionar um pouco de luz aos especialistas em saúde e segurança no trabalho e, neste caso em particular, ao Médico do Trabalho.

A Medicina do Trabalho é uma especialidade médica reconhecida pelo Conselho Federal de Medicina que tem como missão "lidar com as relações entre homens e mulheres trabalhadores e seu trabalho, visando não somente a prevenção dos acidentes e das doenças relacionadas ao trabalho, mas também a promoção da saúde e da qualidade de vida no trabalho"3. Por meio de ações articuladas com equipe multiprofissional transdisciplinar e a representação dos trabalhadores e do empregador, o Médico do Trabalho deve assegurar a cada trabalhador e ao conjunto dos trabalhadores a melhor condição de saúde em toda sua complexidade biopsicossocial e na interação saudável entre as pessoas no ambiente de trabalho. Deve também, objetivar a extensão dessas condições para o meio social e familiar dos trabalhadores ${ }^{4}$.

Além disso deve estar habilitado para atuar em todos os níveis de promoção da saúde. Resumidamente: no nível primário, identificando agentes de risco ocupacional e eliminando ou reduzindo a exposição do trabalhador a eles, ou seja, afastando pessoas sadias das causas de doenças; no nível secundário, estruturando um programa de controle médico de saúde ocupacional que possibilite o diagnóstico e tratamento precoces de agravos decorrentes do trabalho ou a ele relacionados; e, no nível terciário, buscando reduzir e controlar disfuncionalidades e incapacidades adequando o trabalho ao trabalhador.

Considerando a COVID-19, desde o primeiro boletim do MS, os Médicos do Trabalho se movimentaram no sentido de monitorar a saúde dos trabalhadores, particularmente, naquele momento, os "viajantes", tanto na ida, quanto em seu retorno. À medida que a pandemia avançava passaram a orientar os trabalhadores quanto a sintomas suspeitos e medidas preventivas no trabalho e em casa por meio de palestras, informativos, boletins e cartazes. Com a instalação progressiva do "clima de angústia" anteriormente descrito, foram implantados programas de acolhimento e atenção integral à saúde dos trabalhadores e de identificação de trabalhadores em grupo de risco que foram deslocados sempre que possível para trabalho remoto. Foram também rapidamente estruturados procedimentos e ambientes para "busca-ativa" de casos e telemonitoramento de trabalhadores afastados em isolamento domiciliar ou em trabalho remoto, buscando não apenas conhecer seu estado de saúde como também manter o vínculo do trabalhador com seu trabalho. Dando sustentação às necessidades burocráticas e legais trabalhistas foram implantados procedimentos para afastamento do trabalho, encaminhamento para benefício previdenciário e exame médico de retorno ao trabalho, quando fosse o caso.

Enfim, muitas experiências exitosas em Medicina do Trabalho possibilitaram a manutenção da força de trabalho em todos os setores, especialmente nos serviços de saúde evitando desfalques em contingente tão necessário para o enfrentamento da COVID-19. Agora, com as vacinas chegando, a Medicina do Trabalho certamente terá papel fundamental na elaboração, implantação e implementação de programas de vacinação dos trabalhadores. 
Assim, é fundamental a revitalização do SUS e a valorização dos trabalhadores de serviços de saúde, mas é essencial também a valorização da Medicina do Trabalho como especialidade médica envidando todos os esforços na formação diferenciada destes profissionais tanto em programas de residência médica quanto em cursos de especialização.

\section{REFERÊNCIAS}

1. Brasil. Ministério da Saúde. Secretaria de Vigilância em Saúde. Boletim Epidemiológico 04. Disponivel em http:// www.saude.ba.gov.br/wp-content/uploads/2020/02/Boletim-epidemiologico-SVS-04-2.pdf.

2. Johns Hopkins University. Coronavirus Resource Center. COVID-19 Dashboard by the Center for Systems Science and Engineering (CSSE) at Johns Hopkins University. Available from: https://coronavirus.jhu.edu/map.html.

3. Dias EC, Contijo ED, Oliveira RB. Formação, educação continuada e certificação em medicina do trabalho: uma proposta orientada pelas competências requeridas para o exercício profissional. Rev Bras Med Trab. 2003;1(1):6-21. Disponível em: http://www.anamt.org.br/site/upload_arquivos/arquivos_diversos_2052014132387055475.pdf.

4. Dias EC, coordenadora. Competências essenciais requeridas para o exercício da medicina do trabalho: atualização 2016. Curitiba, PR: ANAMT - Associação Nacional de Medicina do Trabalho; 2016. Disponível em: http://www. anamt.org.br/site/upload_arquivos/arquivos_diversos_6620161253357055475.pdf. 